Research Article

\title{
Research on the Geostatic Stress Field Procedure under Complex Conditions
}

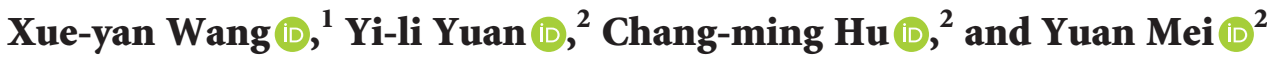 \\ ${ }^{1}$ School of Urban Planning and Municipal Engineering, Xi'an Polytechnic University, Xi'an 710048, Shaanxi, China \\ ${ }^{2}$ College of Civil Engineering, Xi'an University of Architecture and Technology, Xi'an 710055, Shaanxi, China
}

Correspondence should be addressed to Yi-li Yuan; yuan.xauat@qq.com

Received 13 December 2020; Revised 18 March 2021; Accepted 5 April 2021; Published 19 April 2021

Academic Editor: Junping Ren

Copyright ( 92021 Xue-yan Wang et al. This is an open access article distributed under the Creative Commons Attribution License, which permits unrestricted use, distribution, and reproduction in any medium, provided the original work is properly cited.

Geostatic stress field procedure is the first and the most important step for the numerical simulation of geotechnical engineering, which greatly influences the simulation results. Traditional methods often fail when the model is complex. In this paper, based on finite element method (FEM) software ABAQUS, failure reasons of four commonly used methods for the geostatic stress field are studied. According to the analysis results, a new set of methods, which can provide reasonable displacement and stress field results under complex conditions, is proposed. The proposed methods follow the principle that the stress of different materials should be obtained separately to avoid stress distortion. Then, the accuracy and applicability of the proposed method are verified through a comparison study and a specific application. This study provides a theoretical basis for the method of geostatic stress field procedure under complex condition and can serve as a reference for relevant studies.

\section{Introduction}

Geostatic stress (geo-stress) is the natural stress existing in rock and soil structure, also known as the initial stress, absolute stress, or original rock stress of rock and soil mass [1], which is the fundamental factor causing deformation and failure of underground engineering [2]. In the numerical analysis of geotechnical engineering, the geostatic stress field procedure is used to verify that the initial geostatic stress field is in equilibrium with applied loads and boundary. Only when the obtained geostatic stress accurately restores the actual situation of the studied soil, can the simulated problems such as foundation pit excavation or tunnel excavation problems be solved in accordance with the actual situations [3]. Therefore, the geostatic stress field procedure is one of the vital steps for various geotechnical engineering numerical analysis. Zavriyan [4] deduced the theoretical formula of initial stress of truss element in in situ stress analysis. Peng et al. [5] proposed a convenient and stable superposition model to simulate the induced stress and displacement fields around artificial or natural fractures under arbitrarily distributed inner pressures in conjunction with the complex variable method in the theory of elasticity. Meng and He [6] studied the theoretical solution of the hydraulic fracturing equation in a high geo-temperature environment. Pan [7] proposed a method that is applicable to the estimation of gravity-induced horizontal stress in an intact rock mass. Dai et al. [8] analyzed the advantages and disadvantages of several methods for geostatic stress field procedure in ABAQUS through comparative analysis. Xu [9] proposed a method to realize geostatic stress field procedure by directly applying nodal force to the numerical model, which can be used for producing high-precision geo-stress of some complex boundary condition problems. Guo et al. [10] proposed a different geostatic stress field procedure using nodal force based on regression analysis and verified the effectiveness of the proposed method through an example. Akbarov et al. [11] carried out finite element analysis on the geostatic stress field procedure with stress concentration problems. Hou and Ge [12] carried out a systematic summary of the theoretical methods of geostatic stress field procedure. Fu et al. [13], Hu et al. [14], and Zhang et al. [15] studied different types of in situ stress using inversion analysis, respectively. However, in many 
geotechnical analyses, an artificial structure such as retaining piles [16], diaphragm walls [17], or existing buildings [18] is involved. In such analysis, there may be numerical contact problems between the soil and the structure, which may complicate the geostatic stress field procedure $[19,20]$. These problems can be collectively referred to as the stratum-structure geotechnical problems (i.e., the problems involving both stratum and structures) [21]. Commonly used methods often fail to function for these problems. In order to address such problems, this paper proposed a new geostatic stress field procedure based on the analysis of the defects of several commonly used methods and verified the accuracy of the proposed method by comparing analysis and application study.

\section{Flexibility Analysis for Commonly Used Geostatic Stress Field Procedure in ABAQUS}

ABAQUS is a general finite element software. Because of its excellent nonlinear computing capability, ABAQUS has been widely used in the field of geotechnical engineering [22]. ABAQUS will be used in this paper, but the application of the proposed method is not restricted. The geostatic stress field procedure is normally used as the first step of a geotechnical analysis; in such cases, gravity loads and some existing structural loads are applied during this step. Ideally, the loads and initial stresses should exactly equilibrate and produce zero deformations. However, in complex problems, it may be difficult to specify initial stresses and loads that equilibrate exactly.

There are four basic methods for geostatic stress field procedure in ABAQUS: A: automatic method, B: direct defining method, importing methods (which can be further divided into two different methods, i.e., C: importing stress results from output files (odb files of ABAQUS), and D: importing nodal force from output files [23].

2.1. Method A. When method A is invoked, the software automatically computes the equilibrium corresponding to the initial loads and the initial configuration, allowing only small displacements within specified tolerances. The procedure is available with a limited number of elements and materials and is intended to be used in analyses in which the material response is primarily elastic.

2.2. Method B. Method B is used when the initial stress state is approximately known and rather simple so that the stress can be directly given with explicit equations. If the stresses given as initial conditions are far from equilibrium under the geostatic loading and boundary conditions, the method will fail.

2.3. Methods $C$ and $D$. For a rather complex model, that is, whether the model has a complex geometry and boundary conditions or it is a nonlinear constitutive model, methods C and D should be applied. Methods C and D involve two steps: (a) run a regular simulation rather than a geostatic stress field procedure and (b) run the geostatic stress field procedure by importing the stress or nodal results of step a.

To study the flexibility of the four methods under different conditions, three numerical models representing three different complexities are established.

Model 1. Simple model.

Model 2. Model with tie constraint.

Model 3. Model with contact interaction.

The first condition (simple model) represents a model with simple stress state and geometric characteristics, while the other two models represent a model with a complex stress state or geometric characteristics of two different types. The second condition (tie constraint) represents the model with two different parts with no relative displacement at the interface. The third condition (contact interaction) represents the model with two different parts allowing relatively displacement at the interface.

2.4. Model 1: Simple Model. As shown in Figure 1, the model size is $50 \mathrm{~m} \times 50 \mathrm{~m} \times 50 \mathrm{~m}$. Elastic-plastic constitutive model and Mohr-Coulomb yield criterion are applied [24]. The material properties are shown in Table 1. The boundary condition for the bottom, side, and top of the model are fixed, normal constraint, and free, respectively. The simulation model is shown in Figure 2.

Applying four methods to model 1, vertical deformation and vertical stress $\left(\sigma_{\mathrm{z}}\right)$ contours are obtained as shown in Figure 3 and 4 . The calculation results are summarized in Table 2.

The ground displacement caused by the process of foundation pit excavation or tunnel excavation is mostly bigger than $10^{-3} \mathrm{~m}$, and displacement smaller than $10^{-4} \mathrm{~m}$ is usually ignored in engineering practice. Therefore, a $10^{-4} \mathrm{~m}$ level of displacement can be a reasonable upper bound for the results of the geostatic stress field procedure. As shown in Figures 3 and 4 and Table 2, all four methods achieve equilibrium with a displacement smaller than $1 \times 10^{-4} \mathrm{~m}$.

In addition, it can be seen from Figures 3 and 4 that the stress results obtained by the four methods are nearly identical, while the displacement results are quite different. The reason for this phenomenon is that, for a simple model, the four basic methods can obtain the stress results close to the actual stress field but with small differences, which is too small to reflect on the stress contours. But the displacement difference caused by the stress difference is evident.

2.5. Model 2: Model with Tie Constraint. In ABAQUS, to establish a tie constraint between two surfaces is to constrain each of the nodes on one surface to have the same value of displacement as the nodes on the other surface that it contacts. In geotechnical engineering simulation, tie constraint is often used to simulate the relationship between artificial structure and the soil when relative slip can be ignored, such as the interaction between the lining and the surrounding soil in the shield tunnel excavation simulation, the interaction between the foundation and the soil, and the 


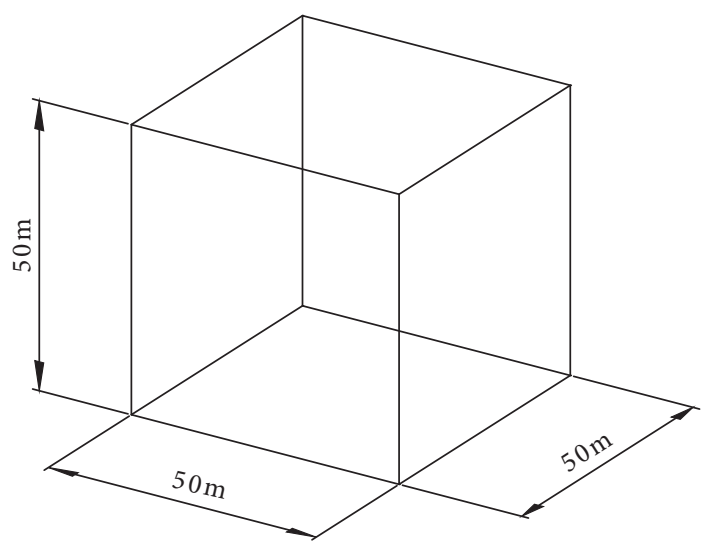

Figure 1: Dimensions of model 1.

TABle 1: Parameters of the materials in model 1.

\begin{tabular}{lccccc}
\hline Material & Elastic modulus $(\mathrm{kPa})$ & Poisson's ratio & Cohesion $(\mathrm{kPa})$ & Friction angle $\left({ }^{\circ}\right)$ & Density $\left(\mathrm{kg} / \mathrm{m}^{3}\right)$ \\
\hline Clay & $1.8 \times 10^{4}$ & 0.35 & 32 & 14 & 2.0 \\
\hline
\end{tabular}

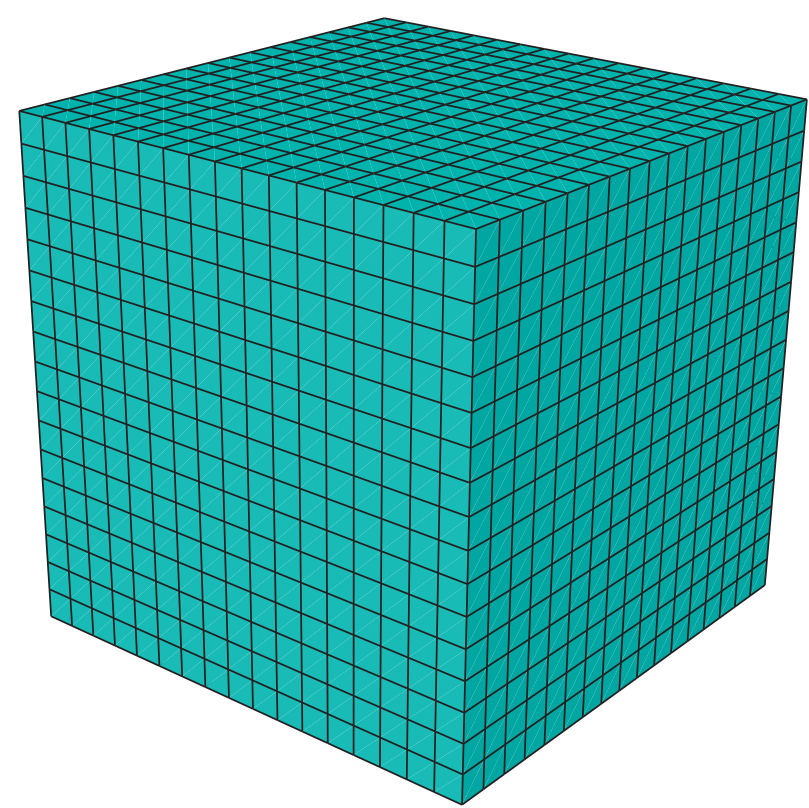

FIgURE 2: FEA model of Model 1.

connection between the retaining pile and the soil in the simulation of foundation pit supporting system. As shown in Figure 5, the model size of model 2 is $100 \mathrm{~m} \times 50 \mathrm{~m} \times 50 \mathrm{~m}$, which is composed of a $50 \mathrm{~m} \times 50 \mathrm{~m} \times 50 \mathrm{~m}$ cube of soil and an identical concrete cube. Material settings of the soil are the same as Section 2.1, while the concrete adopts a linear elastic constitutive model for simplification. Parameters of the materials are shown in Table 3. Boundary conditions are the same as Section 2.1. Additionally, a tie constraint is used to connect the soil model and concrete model. The numerical model is shown in Figure 6.

Only methods $\mathrm{C}$ and $\mathrm{D}$ reach convergence, and the calculation results are obtained (shown in Figures 7 and
8). Methods A and B fail to produce a reasonable stress field in equilibrium with the applied loads and boundary.

It can be seen from Figures 7 and 8 that the results obtained by methods $\mathrm{C}$ and $\mathrm{D}$ are almost identical. This is because the two methods import data from the same output file. For method C, stress field was imported, while the nodal force was imported for method $\mathrm{D}$. The resulting displacement for both methods is relatively large (nearly $6 \times 10^{-4} \mathrm{~m}$ ). Furthermore, stress near the tie surface is distorted. This is because the stress results in the first step of methods C and D are distorted because of the abrupt change of stiffness at the tied surface. 

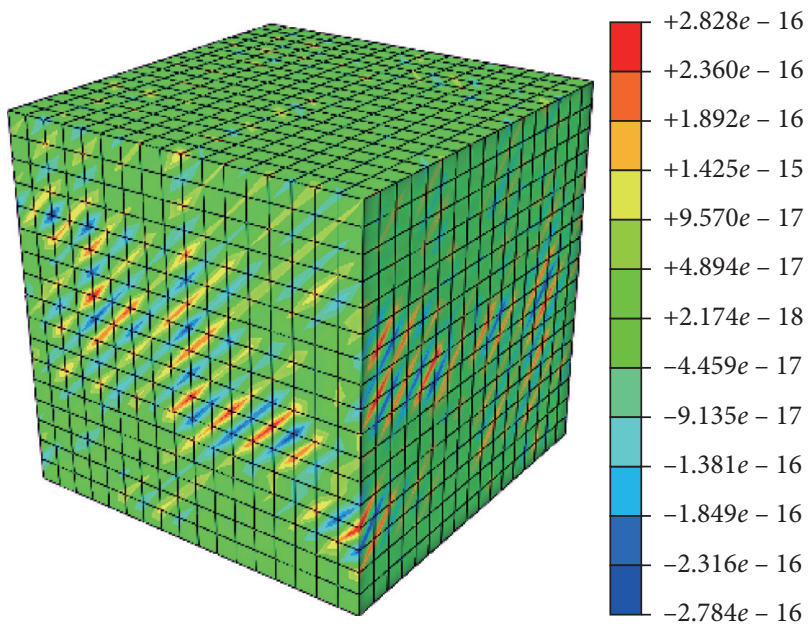

(a)
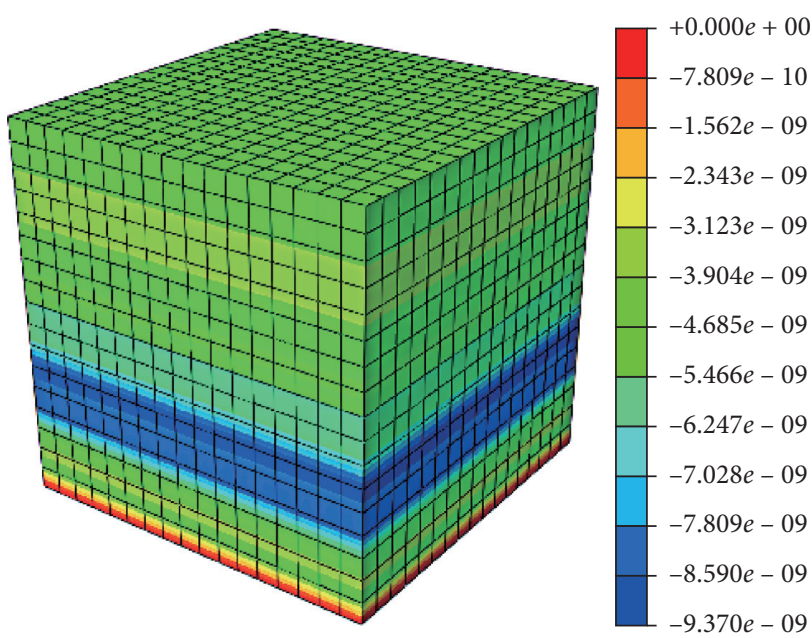

(c)

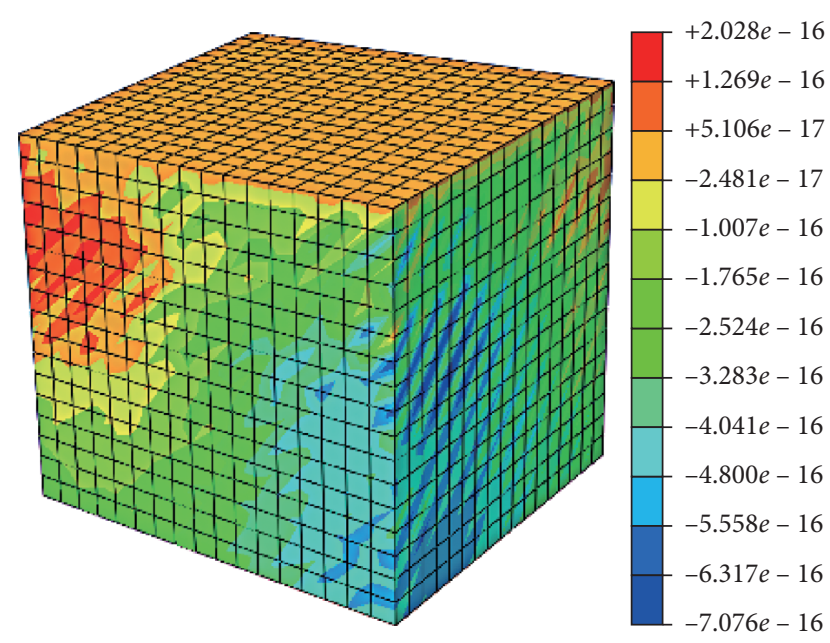

(b)

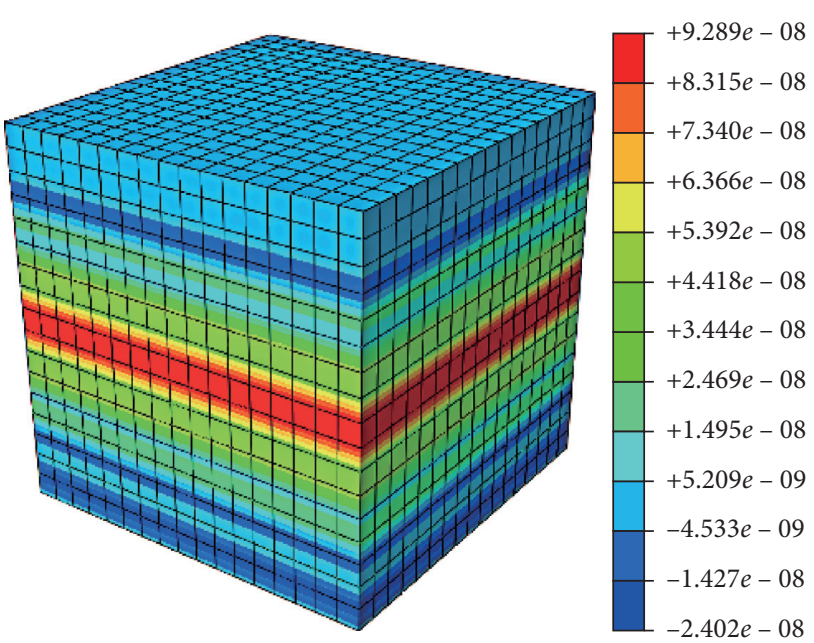

(d)

FIGURE 3: Vertical deformation results for model 1 (unit: m). (a) Method A, (b) method (B), (c) method C, and (d) method D.

Considering the stress distortion results of methods $\mathrm{C}$ and $D$, all the four methods fail to produce a reasonable result for a tie constraint model.

2.6. Model 3: Model with Contact Interaction. In the numerical simulation such as pile-soil interaction simulation, friction contact is often used to simulate the interaction between the pile side surface and soil side surface. Infinite element analysis, contact interaction is a nonlinear boundary condition, which often causes convergence difficulty. The behavior of the four methods was discussed under such conditions.

Settings of model 3 are almost the same as model 2 except that the tie constraint between soil and concrete is replaced by a surface contact interaction (Figure 9). The friction properties are set to hard contact in the normal direction and penalty function in the tangential direction.

Similar to the situation of model 2, only methods C and $\mathrm{D}$ converged, and the calculation results are shown in Figures 10 and 11).
It can be seen from Figures 10 and 11 that the maximum displacement for both methods is approximately $1.3 \times 10^{-2} \mathrm{~m}$, which is far bigger than that requiring $10^{-4} \mathrm{~m}$ standard [3]. Figures 12 and 13 show the displacement of soil and concrete separately. The maximum displacement of both soil and concrete occurs at the interface but in opposite direction. The displacement direction is downwards for soil and upwards for concrete. This is because the stress results were imported but the contact forces were not. In addition, it can be seen from the stress nephogram that, like model 2, the stress near the contact interface is also distorted. The distorted stress is caused by the unexpected friction produced by the relative displacement between two surfaces.

Therefore, the four basic methods cannot produce a reasonable result for a model with contact interaction either.

In summary, four basic methods can come up with reasonable results for a rather simple finite element model with uncomplicated geometry, single material property, and no nonlinear boundary conditions. Since the automatic method is the simplest and produces the most ideal results, it should be used when possible. However, when 


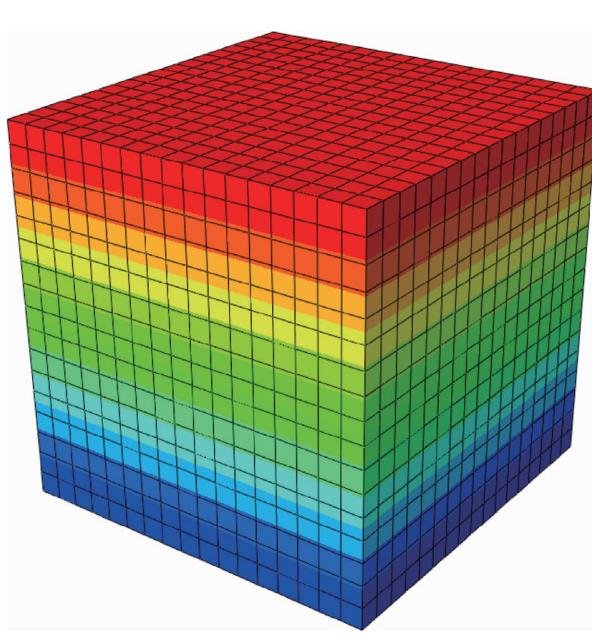

(a)

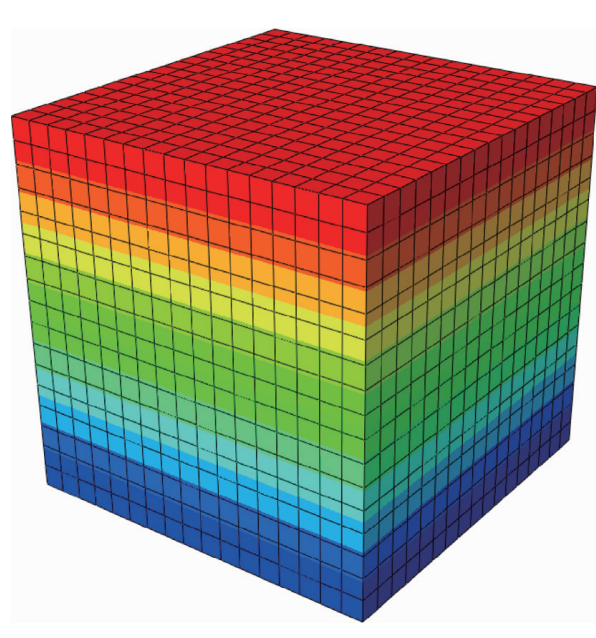

(c)
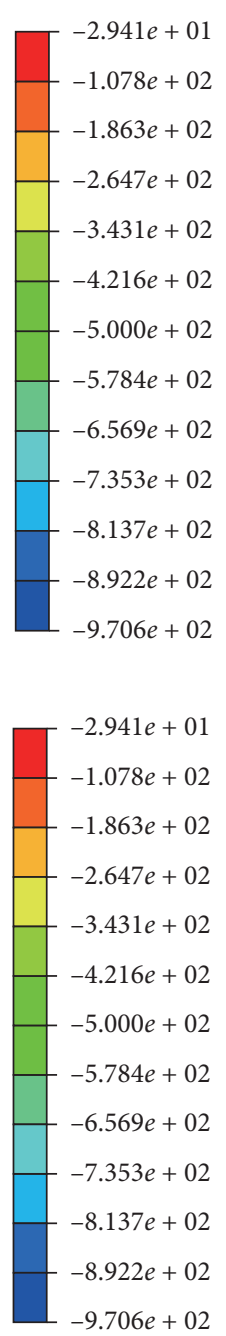

$-9.706 e+02$
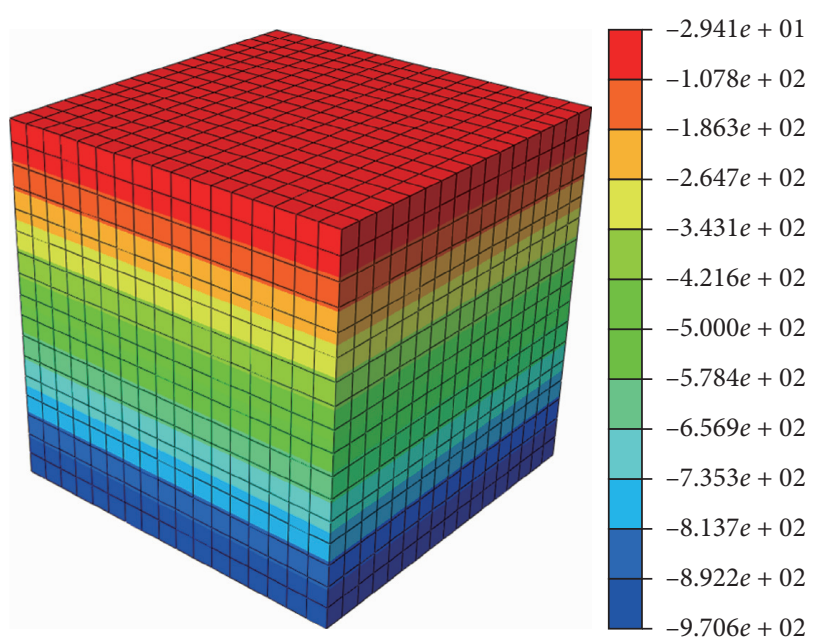

(b)
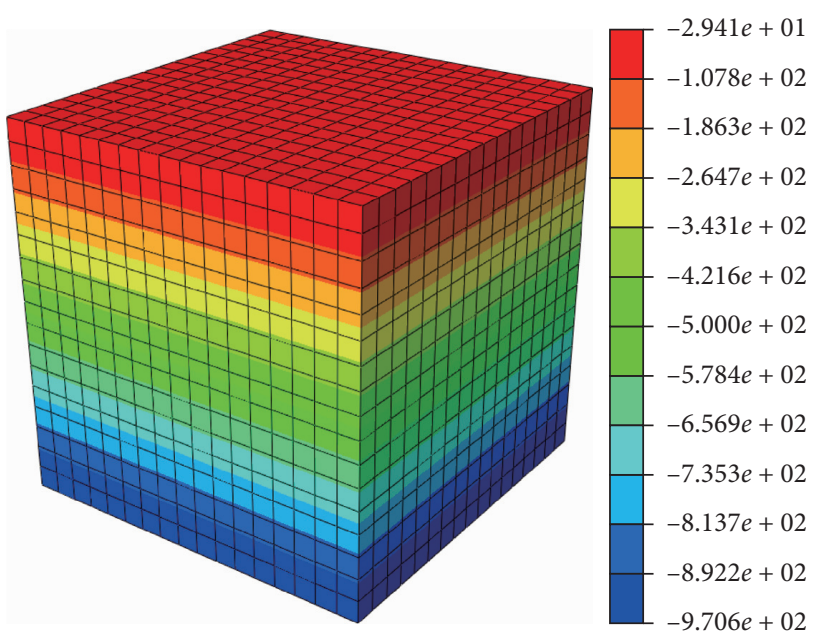

(d)

Figure 4: Stress results for model 1 (unit: kPa). (a) Method A, (b) method B, (c) method C, and (d) method D.

TABLE 2: Table of the simulation results.

\begin{tabular}{lccc}
\hline Method & Max stress $(\mathrm{kPa})$ & Max displacement $(\mathrm{m})$ & Conclusion \\
\hline Method A & $-9.706 \times 10^{2}$ & $2.828 \times 10^{-16}$ & Equilibrium acquired \\
Method B & $-9.706 \times 10^{2}$ & $7.076 \times 10^{-16}$ & Equilibrium acquired \\
Method C & $-9.706 \times 10^{2}$ & $9.370 \times 10^{-09}$ & Equilibrium acquired \\
Method D & $-9.706 \times 10^{2}$ & $9.289 \times 10^{-8}$ & Equilibrium acquired \\
\hline
\end{tabular}

nonlinear boundary conditions such as tie constraint or contact interaction were involved, which is quite common in the numerical simulation in foundation pit excavation or tunneling, all four methods are unable to function properly.

\section{Method for Geostatic Stress Field Procedure for Complex Model}

In the numerical simulation of geotechnical engineering problems, the interaction of soil layers and artificial structure in a model can be pretty complex, such as the simulation of the influence of the excavation of foundation pit on existing structures, or the excavation simulation or slope stability analysis considering the retaining pile. For these sorts of problems, the geostatic stress field procedure will be difficult because of the poor performance of the commonly used methods. In this study, a new method for geostatic stress field procedure is proposed to deal with these problems.

According to the analysis in the above section, the reasons for the failure of the basic methods lie in the huge stiffness difference between soil and artificial structure material such as steel and concrete. Because of the stiffness 


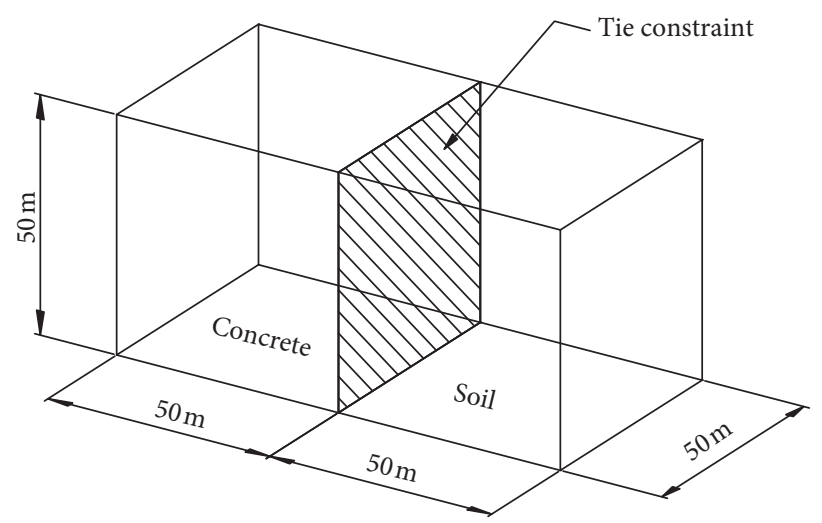

FIGURE 5: Dimensions of model 2.

TABle 3: Parameters of the materials in Model 2.

\begin{tabular}{lccccc}
\hline Material & Elastic modulus $(\mathrm{kPa})$ & Poisson's ratio & Cohesion $(\mathrm{kPa})$ & Friction angle $\left(^{\circ}\right)$ & Density $\left(\mathrm{kg} / \mathrm{m}^{3}\right)$ \\
\hline Soil & $1.8 \times 10^{4}$ & 0.35 & 32 & 14 & 20 \\
Concrete & $3.15 \times 10^{7}$ & 0.2 & - & - & 25 \\
\hline
\end{tabular}

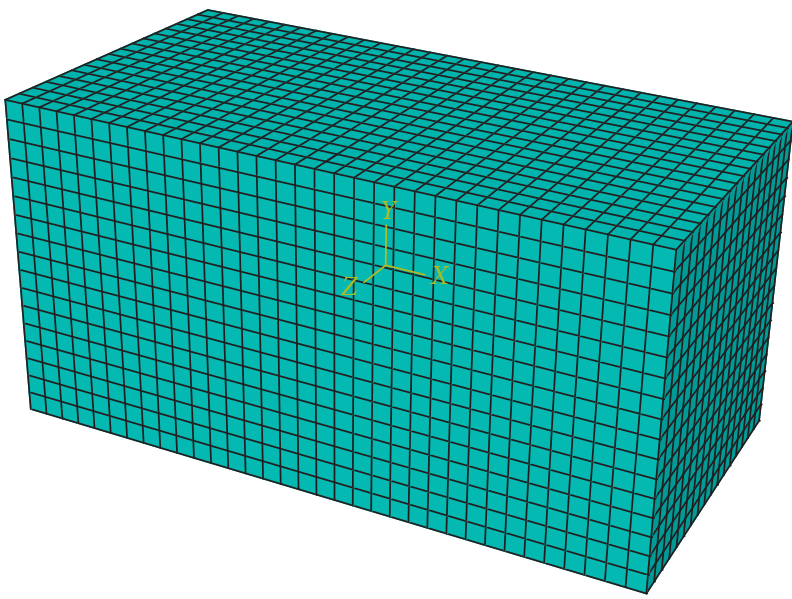

Figure 6: FEA model of model 2.

difference, relative displacement occurs at the interface of the soil and artificial structure, which will lead to a redundant stress increment that makes the acquired stress field inappropriate, and thus the displacement cannot meet the requirement. Since the redundant stress near the interface is the main cause of the failure of the geostatic stress field procedure, avoiding the redundant stress during the geostatic stress field procedure may be a practicable approach.

Therefore, the following geostatic stress field procedure was proposed and verified by applying to model 2 and model 3. The proposed method follows the principle that the stress of different materials should be obtained separately to avoid stress distortion.

3.1. Method Description. The proposed method contains two similar forms to deal with the tie constraint and contact interaction conditions.
(1) For tie constrained:

(1) Remove the tie constraint that connects soil and artificial structures in the model, and apply appropriate displacement boundary conditions to the corresponding surface of the model (for the above example, the applied displacement boundary condition for model 2 should be zero normal displacement on both sides of soil and concrete).

(2) Run a static analysis of the model, and import the output file to the geostatic stress field procedure.

(3) Restore the tie constraints and run the geostatic stress field procedure.

(2) For contact interaction:

(1) Remove the contact interaction that connects soil and artificial structures in the model, and apply 


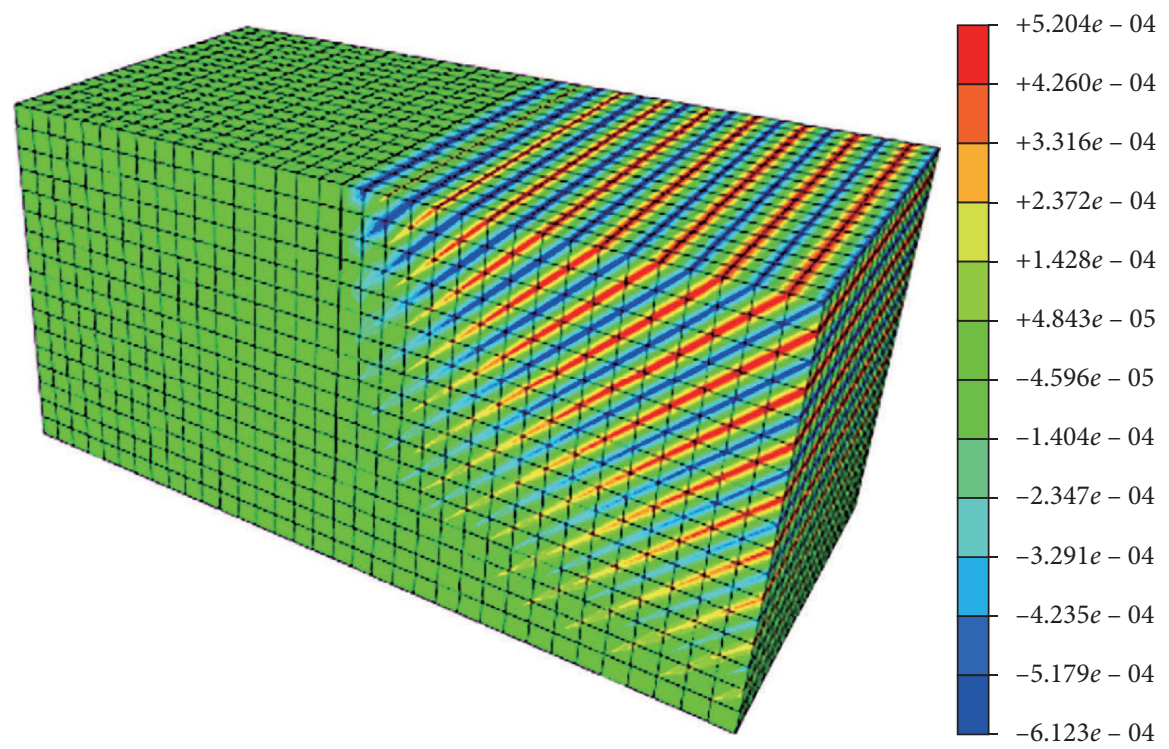

(a)

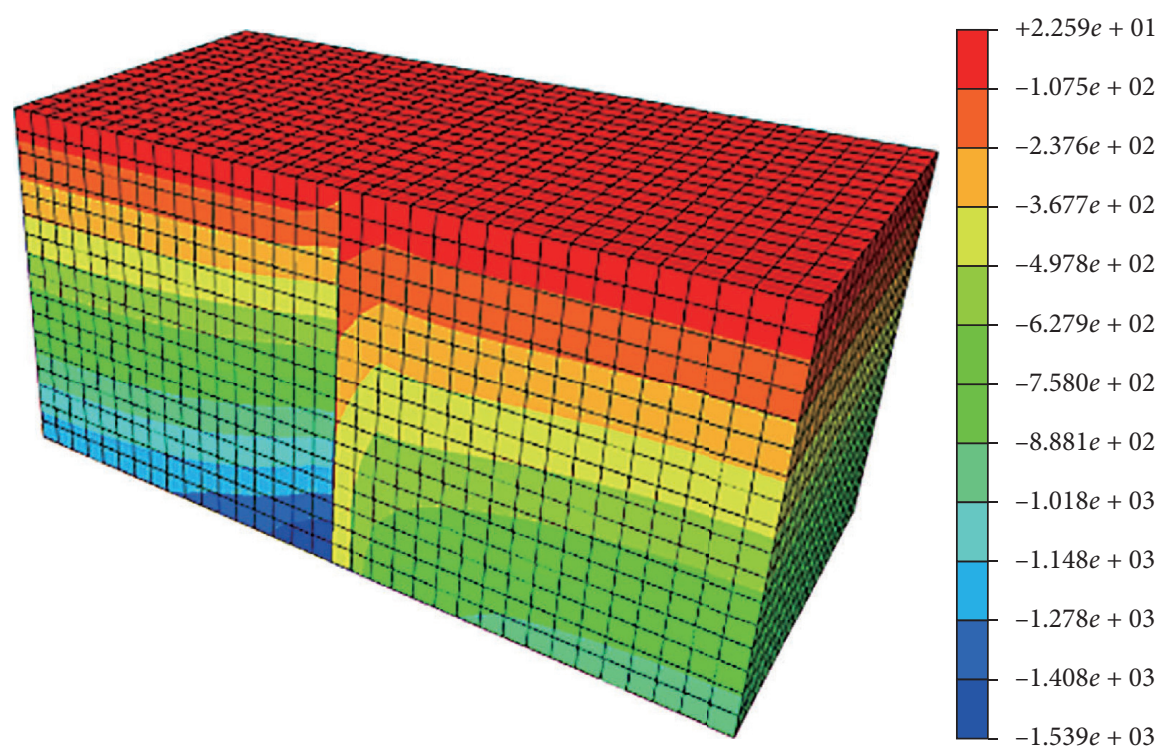

(b)

Figure 7: Simulation results of method C. (a) Vertical displacement results (unit: m) and (b) vertical stress results (unit: kPa).

appropriate displacement boundary conditions to the corresponding surface of the model, or set the friction coefficient to zero so that the contact interaction can act as a zero normal displacement boundary condition.

(2) Run a static analysis of the model, and import the output file to the geostatic stress field procedure.

(3) Restore the contact interaction and run the geostatic stress field procedure, or restore the friction coefficient and run the geostatic stress field procedure.

If each part of the model is simple enough for the automatic method, then the method can be simplified as follows:
(1) Deactivate the contact interaction (or set the friction coefficient to zero) at the first step of the simulation, and use the automatic method to run the geostatic stress field procedure for each part of the model.

(2) Activate the contact interaction (or restore the friction coefficient) at the second step and run a static analysis.

3.2. Verification of the Proposed Method. The proposed method is applied to model 2 and model 3 to verify the validity and accuracy of the method. 

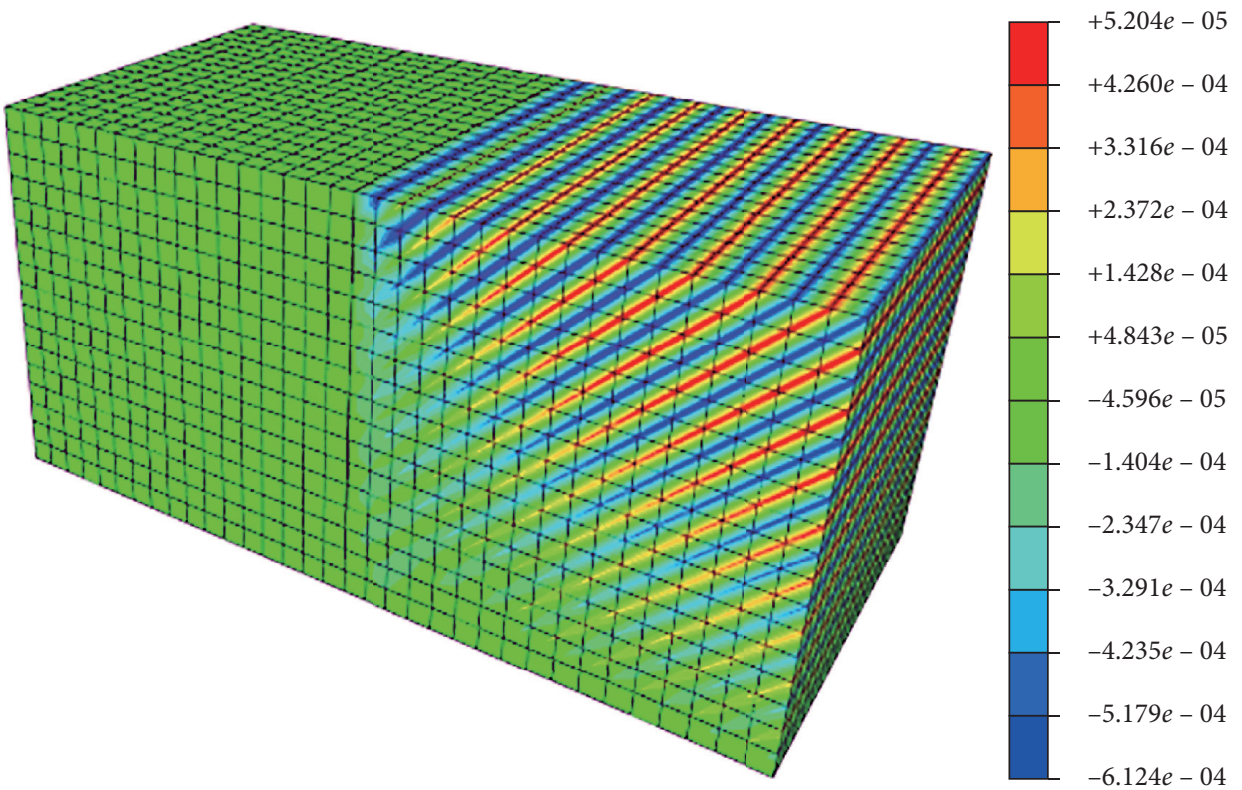

(a)
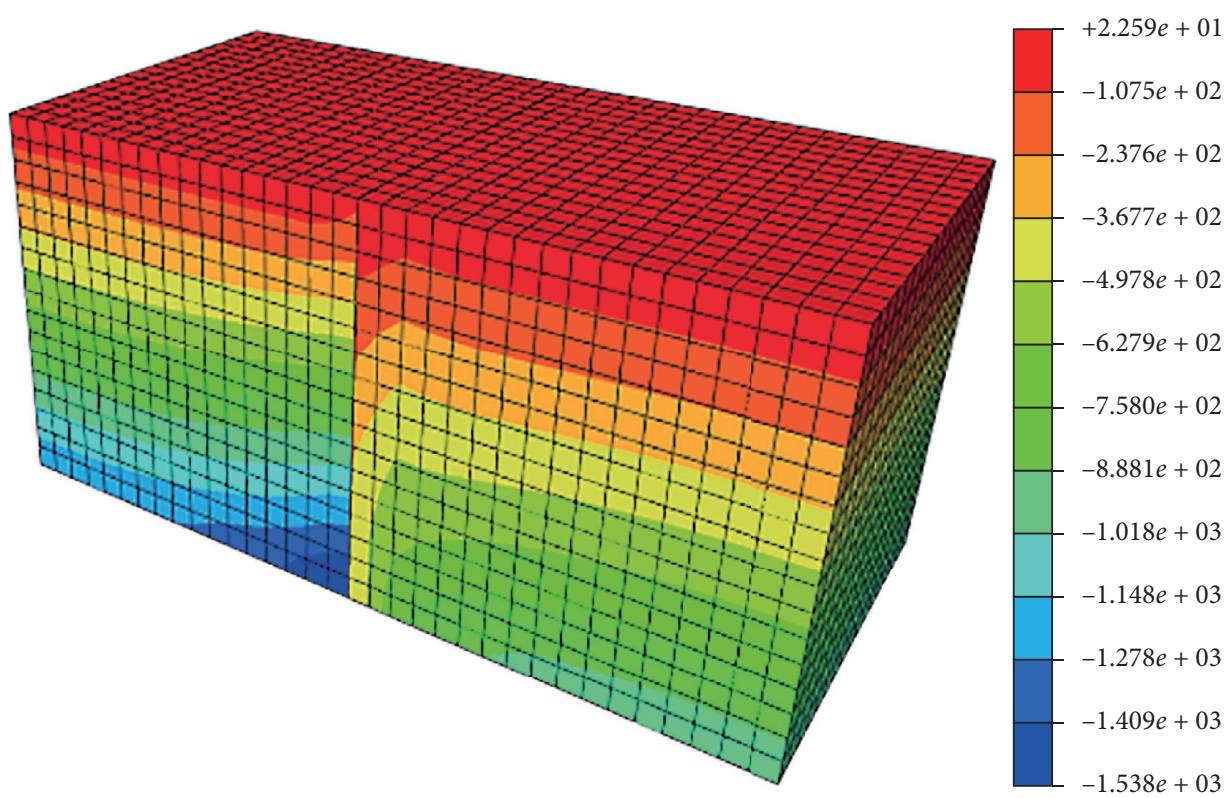

(b)

FIGURE 8: Simulation results of method D. (a) Vertical displacement results (unit: $\mathrm{m}$ ) and (b) vertical stress results (unit: kPa).

\section{(1) Model 2}

Displacement and stress results of the proposed method applying to the tie constraint are shown in Figures 14 and 15,

(2) Model 3

Displacement and stress results of the proposed method applying to the contact interaction model are shown in Figures 16 and 17.

According to Figures 14-17, the maximum displacement for both models is approximately $5 \times 10^{-5} \mathrm{~m}$. The produced stress field is not distorted on the joint area. Therefore, the proposed method is adequate for complex models. Although only ABAQUS is used in this paper to demonstrate the procedure, the proposed method is also available for other FEM software such as ANSYS and MIDAS.

\section{Practical Application of the Proposed Method}

The accuracy and applicability of the proposed method are further verified through the simulation of two practical engineering applications.

4.1. Finite Element Analysis of Deep Foundation Pit Excavation. The first practical engineering case is the excavation of a deep foundation pit of a subway station. The depth and 


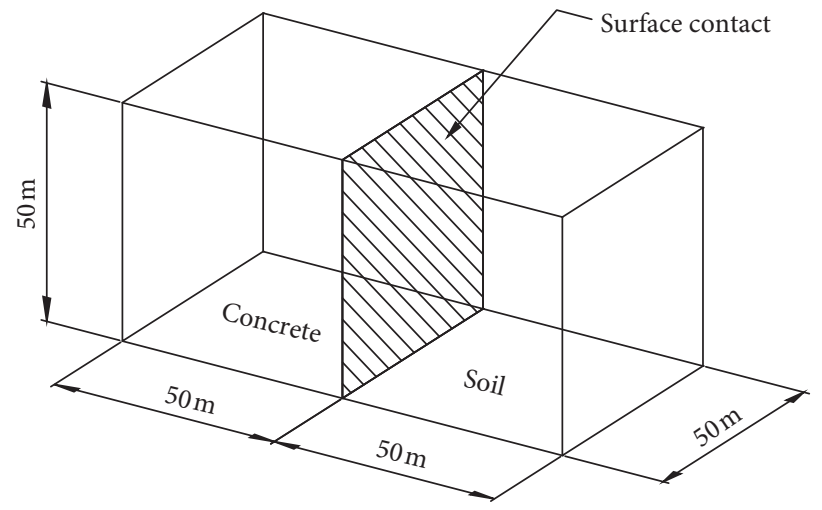

FIgURE 9: Dimensions of model 3.
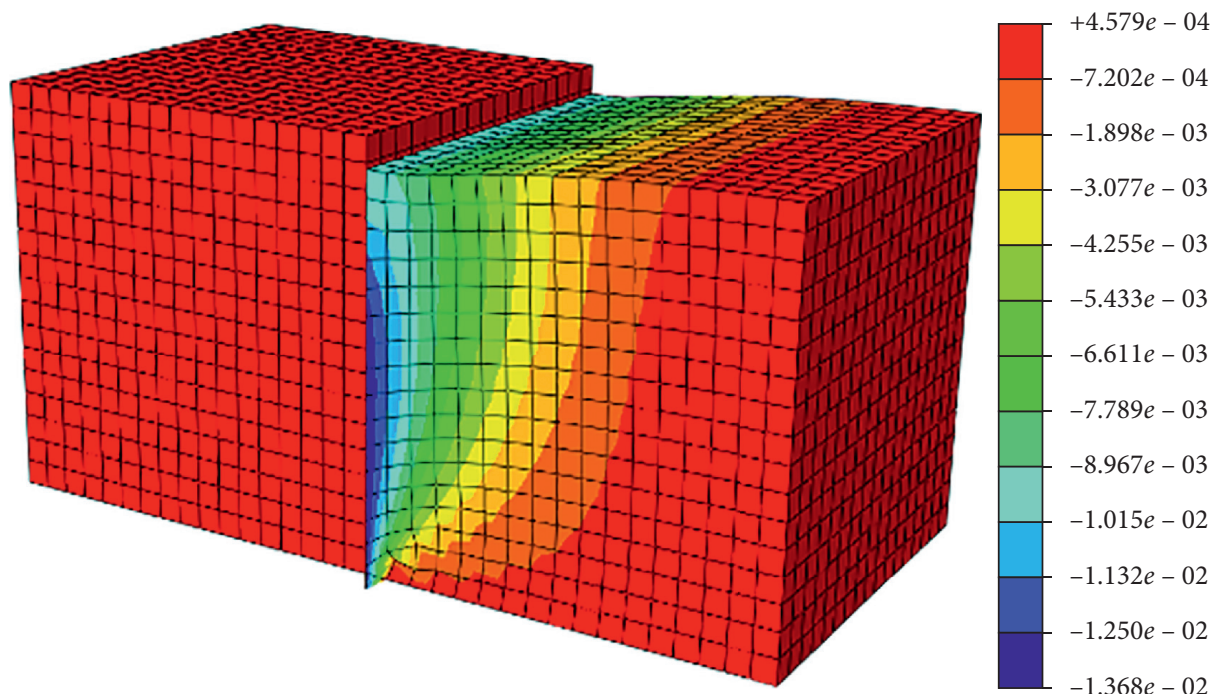

(a)
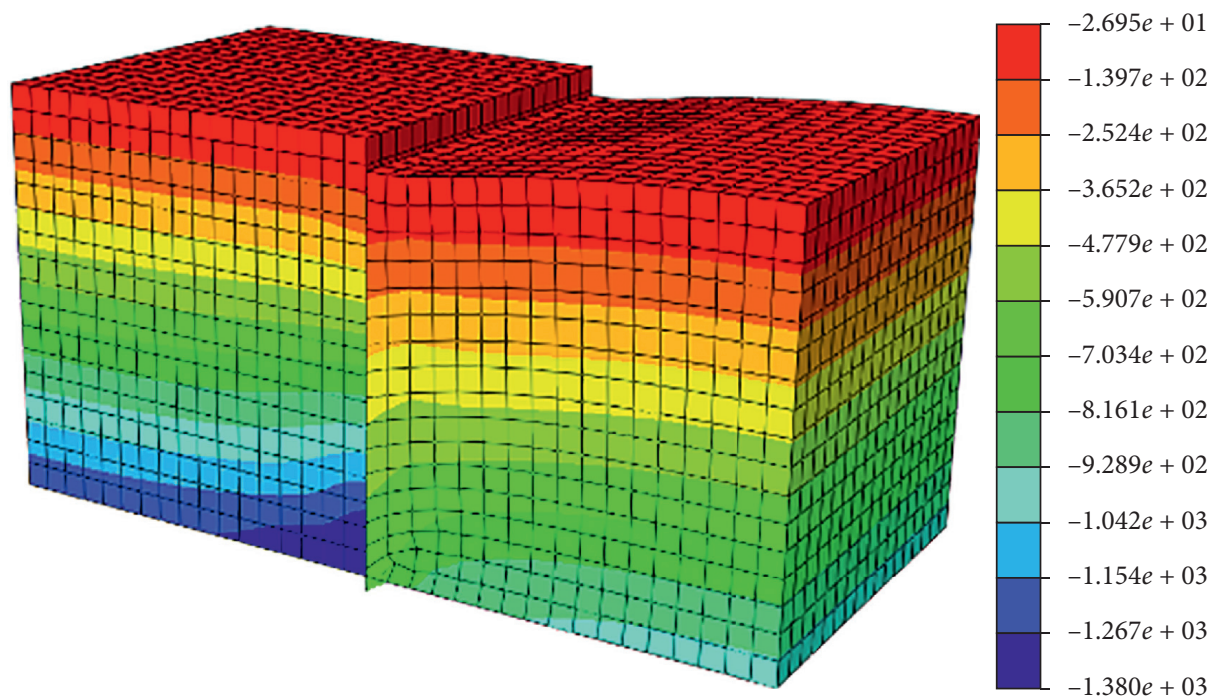

(b)

FIGURE 10: Simulation results of method C. (a) Displacement results (unit: m) and (b) vertical stress results (unit: kPa). 


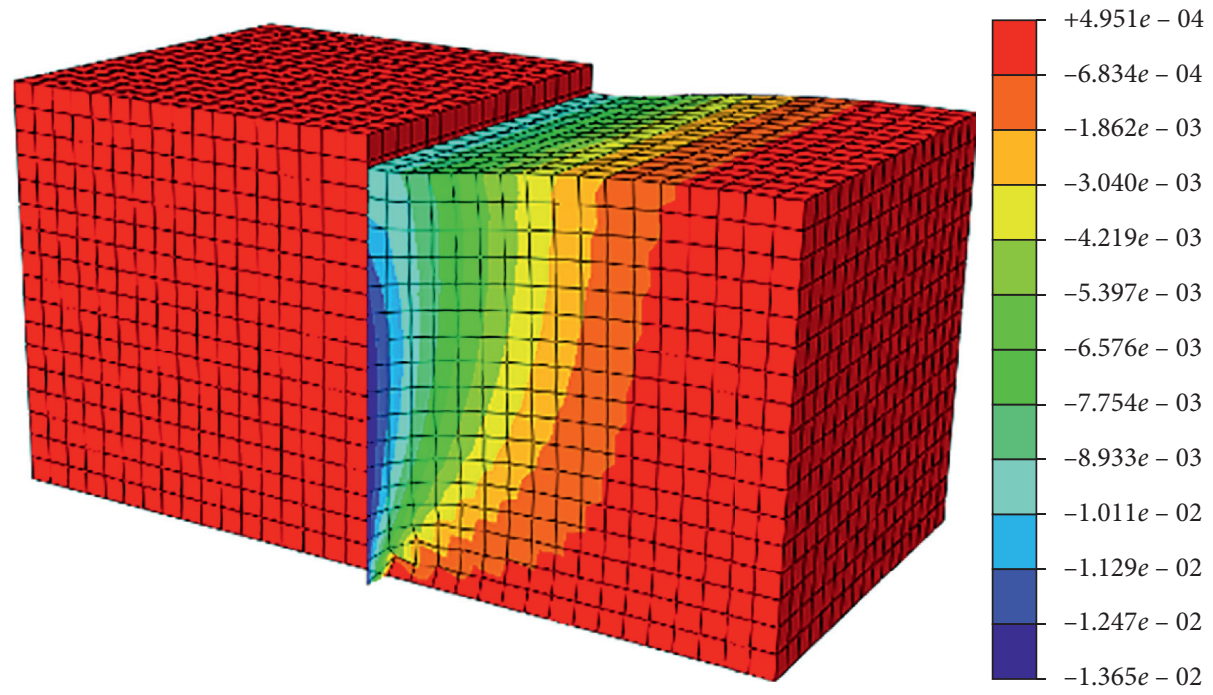

(a)

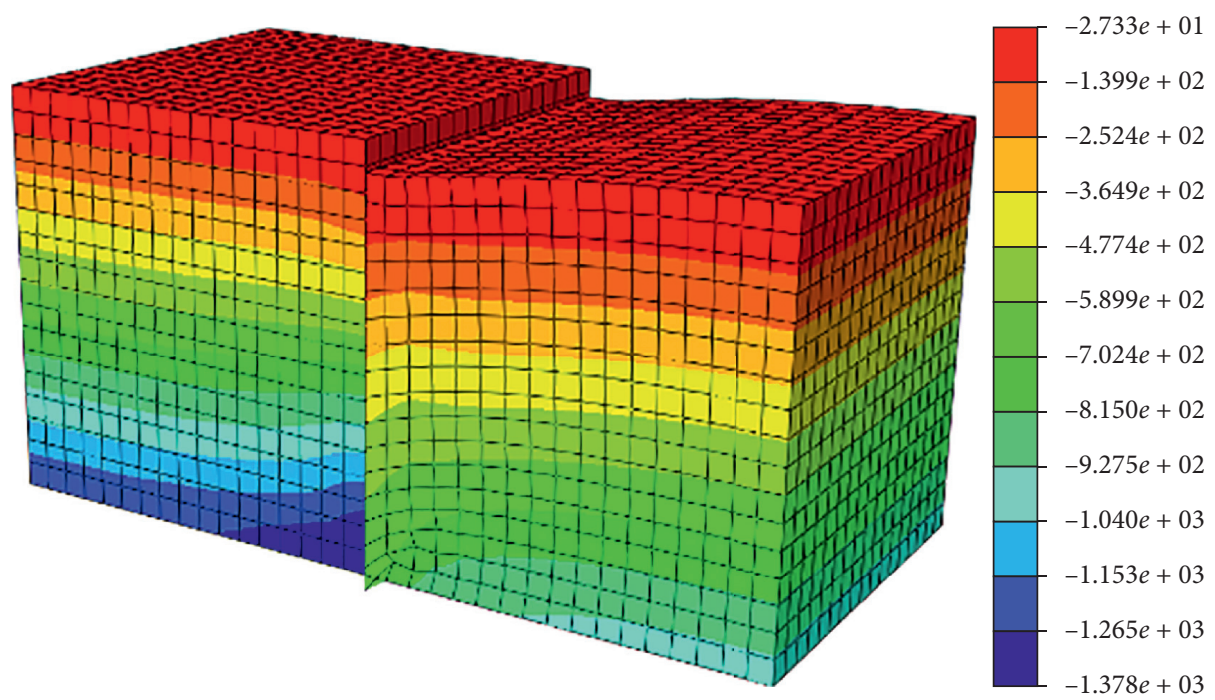

(b)

FIGURE 11: Simulation results of method D. (a) Displacement results (unit: m) and (b) vertical stress results (unit: kPa).

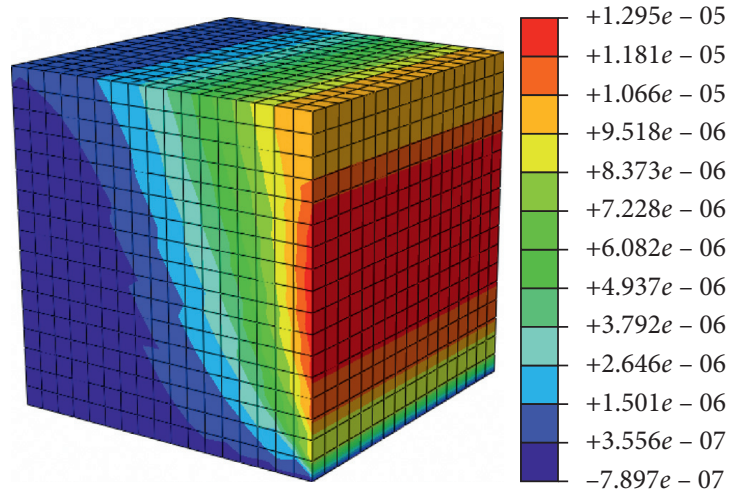

Figure 12: Vertical deformation contours of concrete (unit: m). 


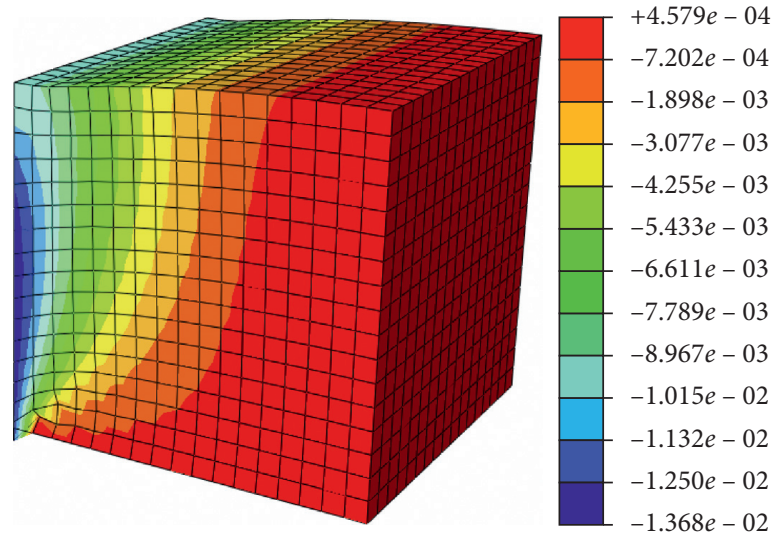

Figure 13: Vertical deformation contours of soil (unit: m).

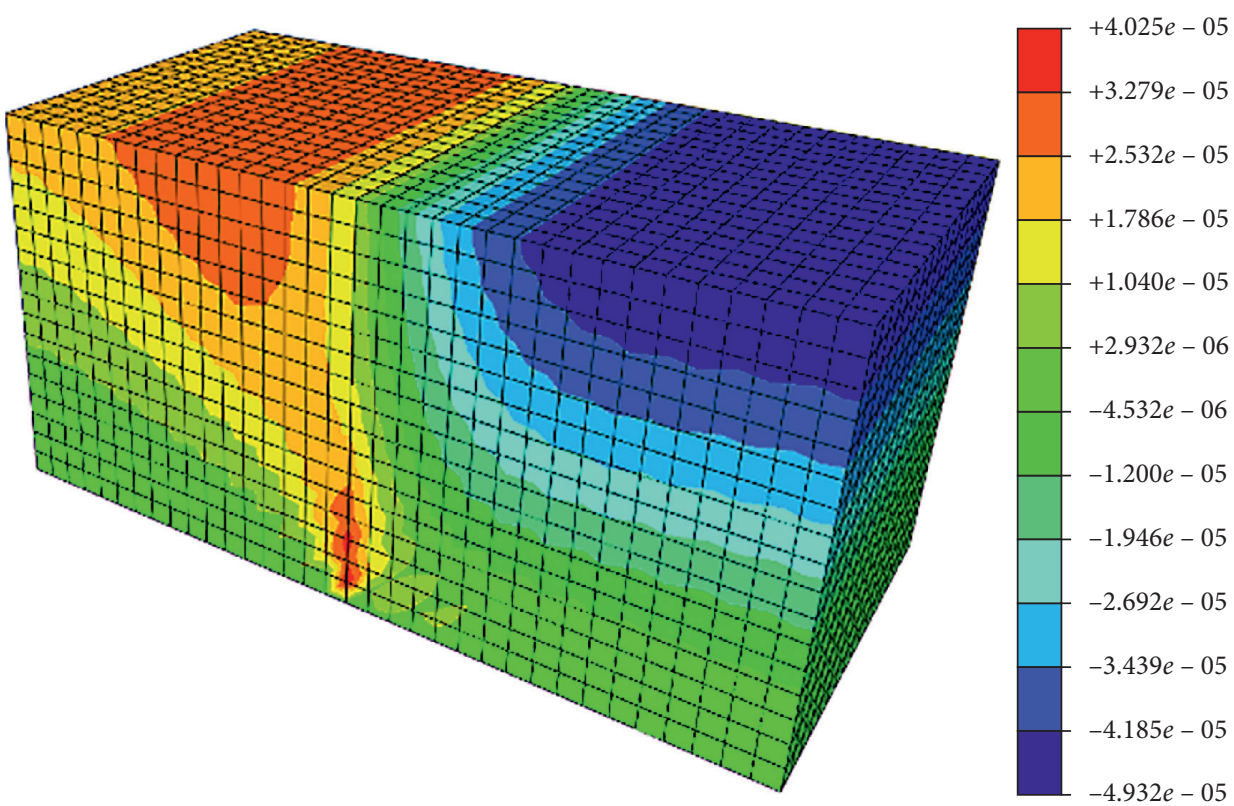

Figure 14: Vertical deformation contours of model 2 (unit: m).

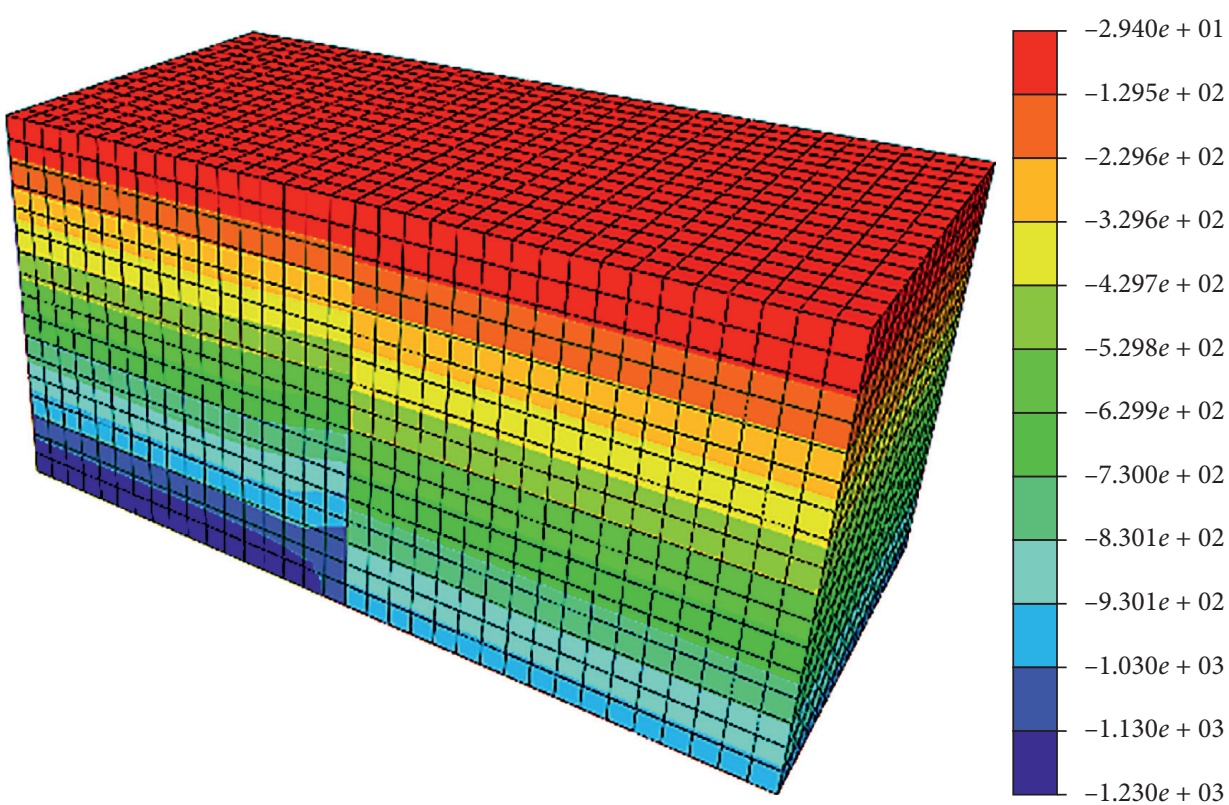

FIGURE 15: Stress contours of model 2 (unit: $\mathrm{kPa}$ ). 


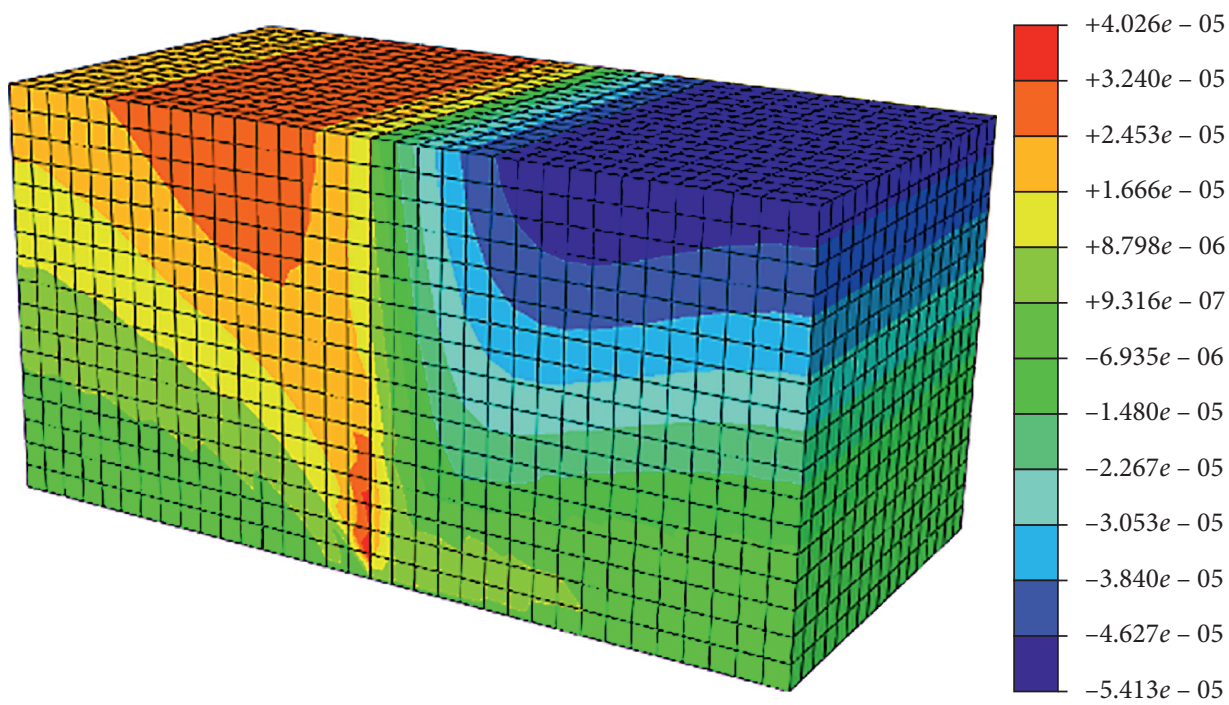

FIGURE 16: Vertical deformation contours of model 3 (unit: m).

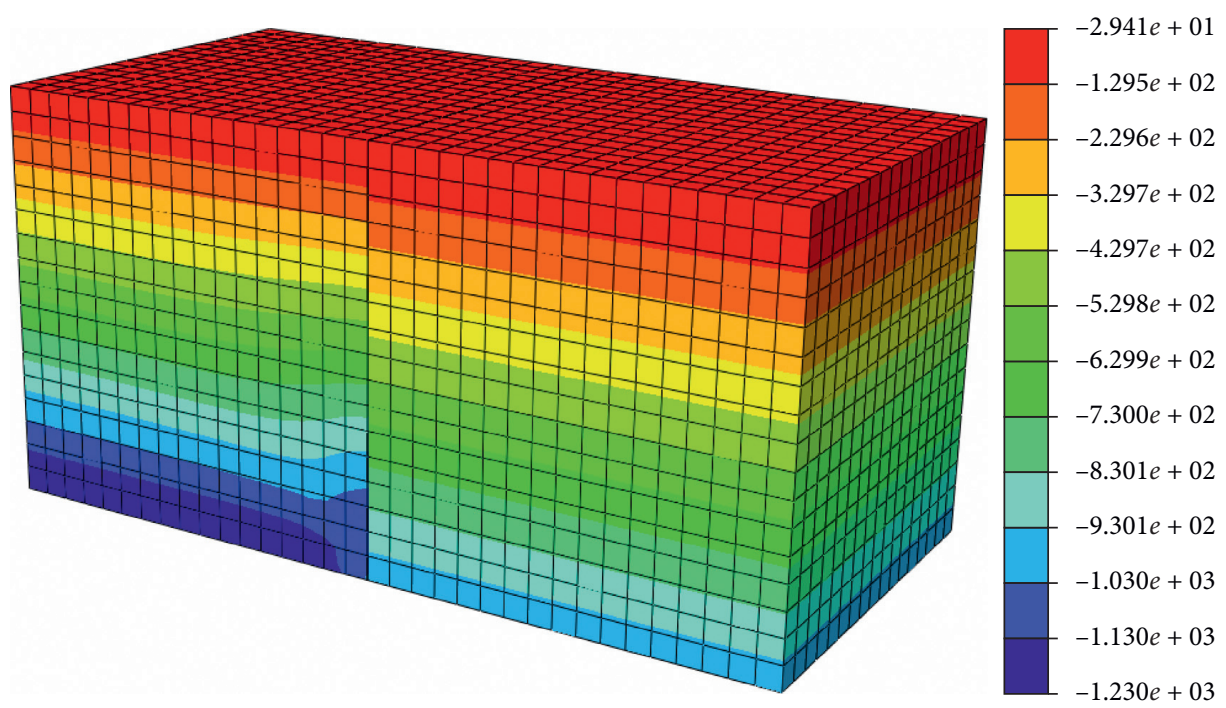

Figure 17: Stress contours of model 3 (unit: $\mathrm{kPa}$ ).

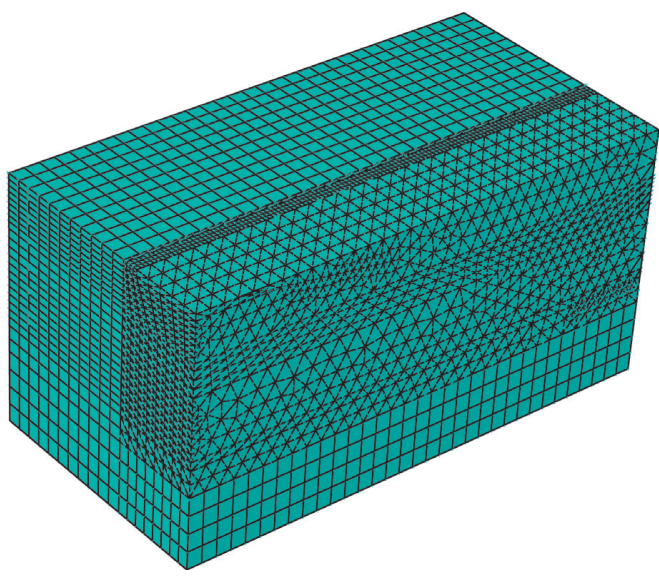

(a)

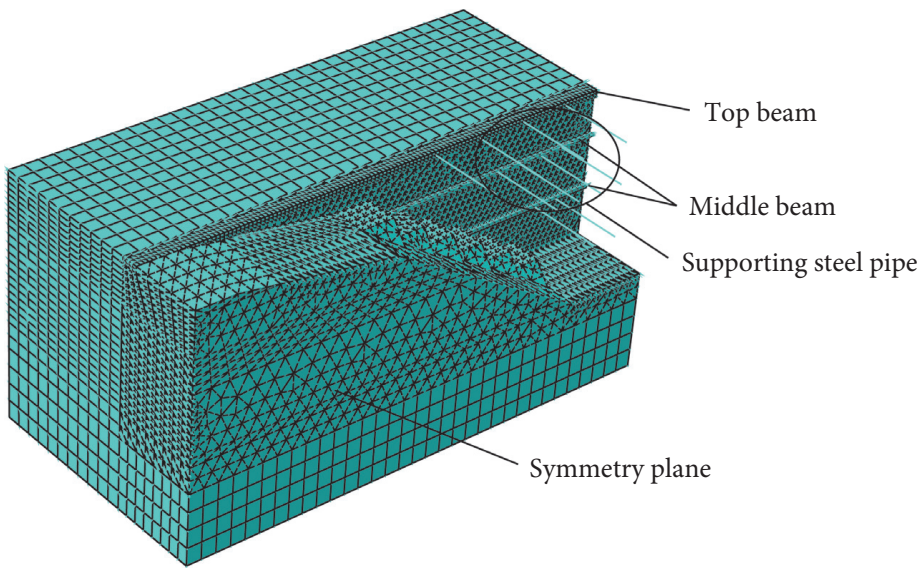

(b)

FIgURE 18: Model before and after excavation. (a) Before excavation. (b) After excavation. 


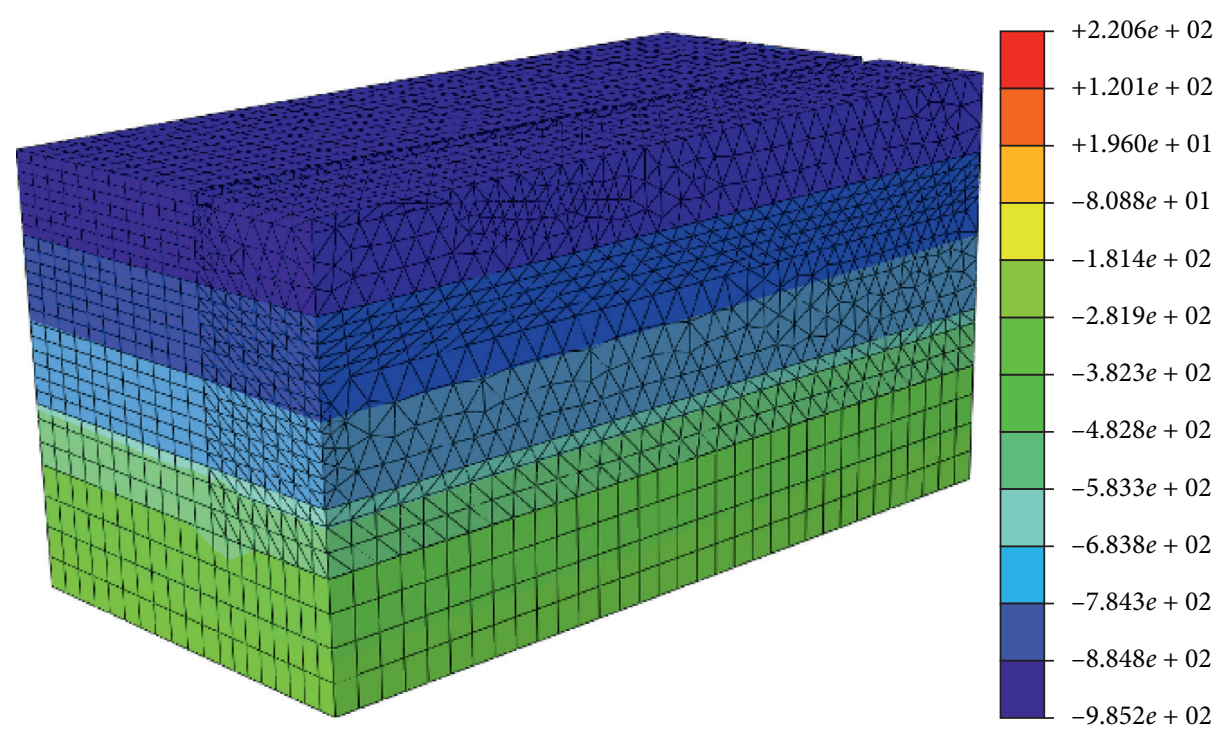

FIgURE 19: Vertical stress contours (unit: $\mathrm{kPa}$ ).
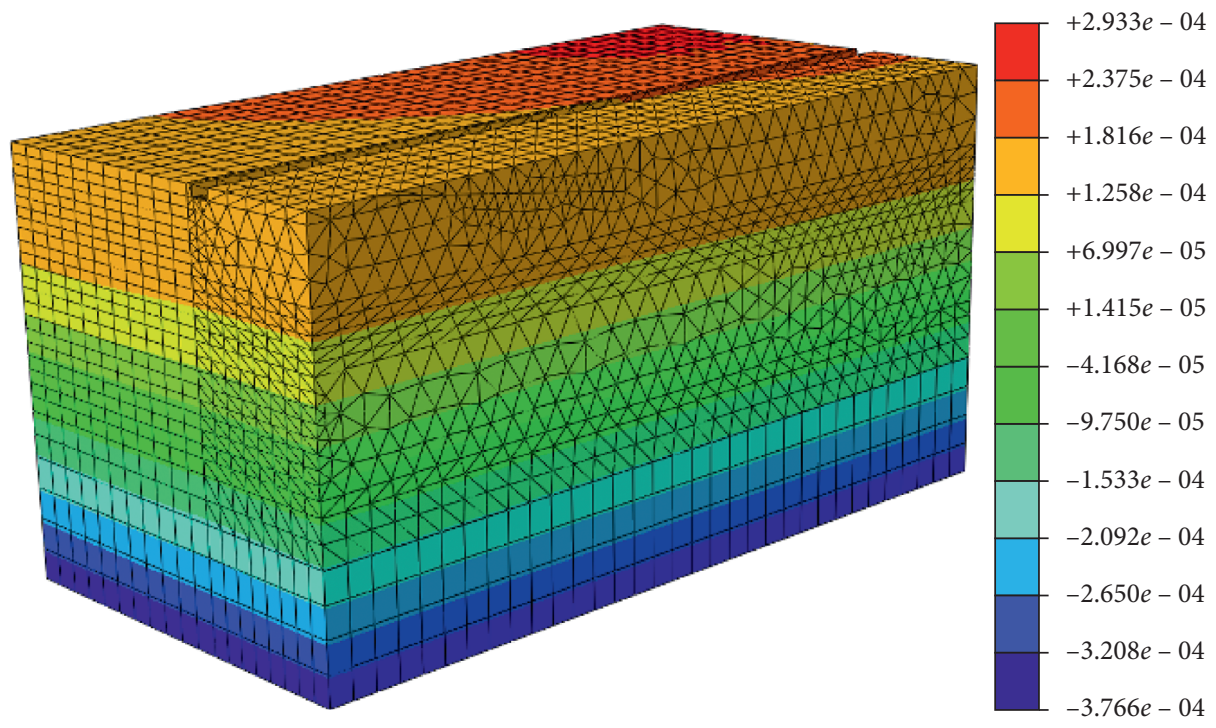

Figure 20: Vertical deformation contours (unit: m).

width of the foundation pit are $18 \mathrm{~m}$ and $19.2 \mathrm{~m}$, respectively. The foundation pit adopts the combined support system composed of supporting pile, top beam, middle beam, and supporting steel pipe. The initial state of the model is shown in Figure 18(a), while the final state is shown in Figure 18(b). In the model, solid elements were used to simulate the soil, top beam, and middle beam; beam elements were used to simulate the supporting steel pipe. Soil, top beam, middle beam, and supporting steel pipe were all connected by tie constraint. Therefore, the first form of the proposed method is used. Results of the geostatic stress field procedure are shown in Figures 19 and 20.
According to Figures 19 and 20, the proposed method produces a reasonable and well-layered stress field, and the displacement results also meet the requirement.

4.2. Analysis of Pile-Soil Interaction. The second practical engineering case is the bearing capacity test of a friction pile. The diameter and length of the pile are $2 \mathrm{~m}$ and $55 \mathrm{~m}$, respectively. Axisymmetric modeling is used for the model (see Figure 21). Contact interaction is used to simulate the relation between soil and pile. Therefore, the second form of the proposed method is used. The model simulates the 


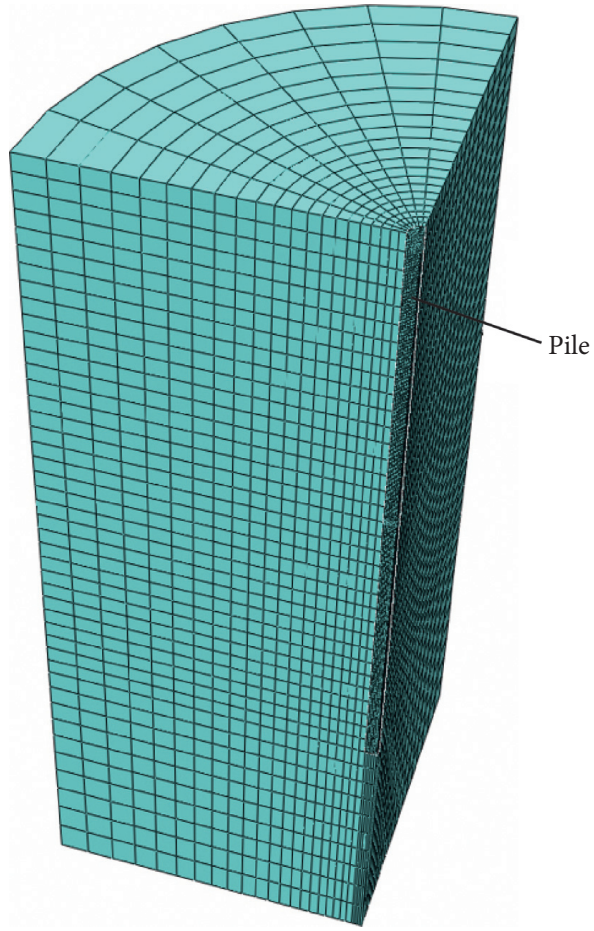

Figure 21: Model of the pile-soil interaction.

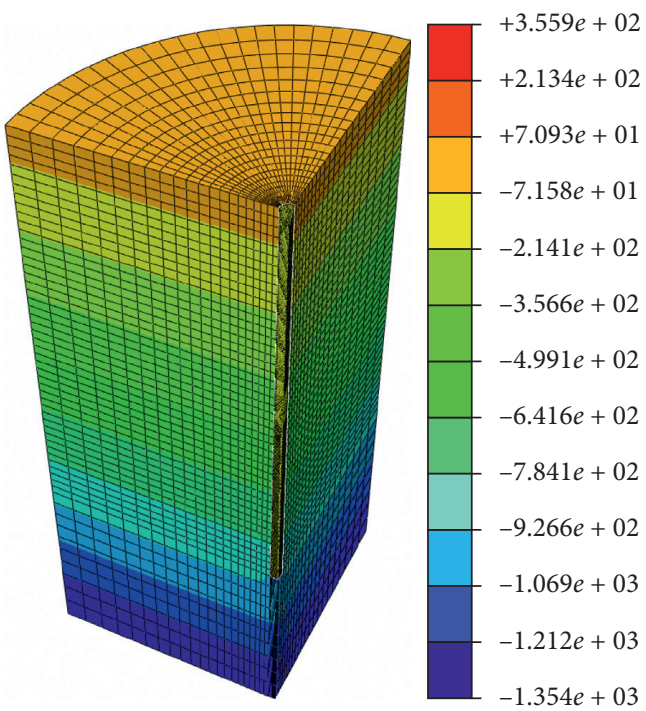

Figure 22: Stress contours of pile-soil interaction.

response of piles under different loads. Results of the geostatic stress field procedure are shown in Figures 22 and 23. The test results and the simulation results of the bearing capacity test are shown in Figure 24.

From the displacement and stress results in Figures 22 and 23 , it can be concluded that the proposed method produces a reasonable and well-layered stress field, and the displacement results also meet the requirement. Comparison of the test results and the simulation results also shows the accuracy of the proposed method.

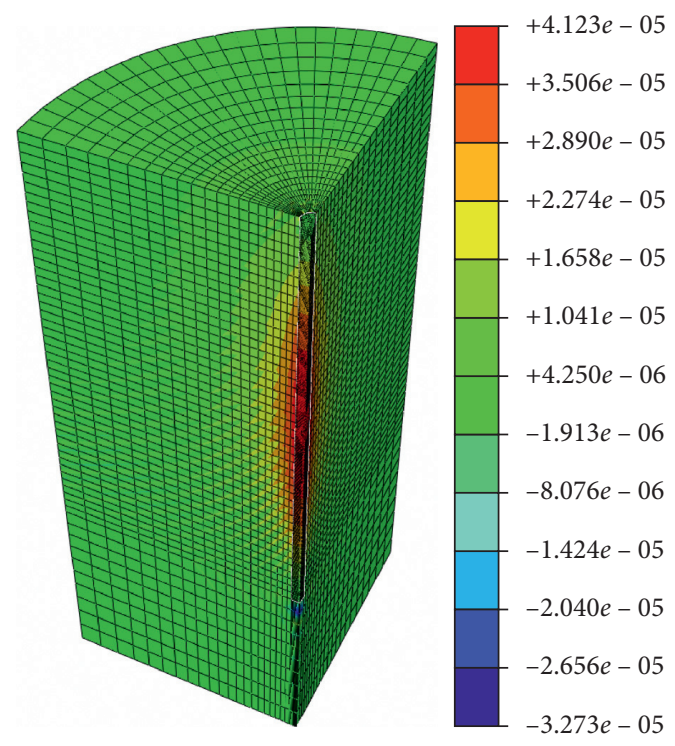

FIgURE 23: Vertical deformation contours of pile-soil interaction.

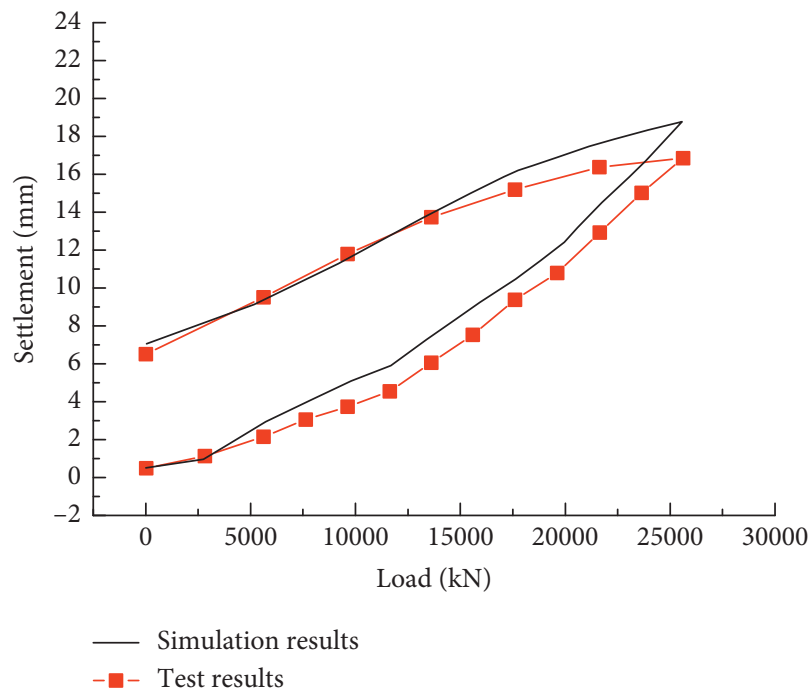

Figure 24: Comparison of the simulated deformation results and monitoring data of the model.

\section{Conclusion}

In this study, four commonly used methods for the geostatic stress field procedure were applied to three models with different complexities to investigate the flexibility of the methods. When the model involves tie constraints or contact interactions, none of the four methods can produce a reasonable result. The reason for the failure of the methods is the distorted stress distribution near the adjacent area caused by stiffness difference between materials such as soil and concrete.

According to the analysis of the failure of the commonly used methods, a new method was proposed to overcome the defect of the commonly used methods. The proposed 
methods follow the principle that the stress of different materials should be obtained separately to avoid stress distortion.

Finally, the accuracy and applicability of the proposed methods were proved through the comparison with the commonly used methods and the application to two practical engineering applications. The proposed method is a good solution for the geostatic stress field procedure under complex conditions.

\section{Data Availability}

The data used to support the findings of this study are available from the first author upon request.

\section{Conflicts of Interest}

The authors declare that there are no conflicts of interest regarding the publication of this paper.

\section{Acknowledgments}

This work was supported by the Key Research and Development Project of Shaanxi Province (Grant nos. 2020SF-373 and 2021SF-523) and the Special Research Project of Shaanxi Provincial Education Department (Grant no. 19JK0381).

\section{References}

[1] M.-f. Cai and L. Qiao, Geostress Measurement Principle and Technology, Science Press, Beijing, China, 1995.

[2] X. Shen, X. Niu, W. Lu et al., "Rock mass utilization for the foundation surfaces of high arch dams in medium or high geo-stress regions: a review," Bulletin of Engineering Geology and the Environment, vol. 76, no. 2, pp. 795-813, 2017.

[3] B. Behera, A. Yadav, G. S. P. Singh, and S. K. Sharma, "Numerical modeling study of the geo-mechanical response of strata in longwall operations with particular reference to indian geo-mining conditions," Rock Mechanics and Rock Engineering, vol. 53, no. 4, pp. 1827-1856, 2020.

[4] E. G. Zavriyan, "Determination of the initial stresses in mine working supports by the relief method," Soviet Mining Science, vol. 6, no. 5, pp. 589-590, 1970.

[5] Y. Peng, Y. Li, and J. Zhao, "A novel approach to simulate the stress and displacement fields induced by hydraulic fractures under arbitrarily distributed inner pressure," Journal of Natural Gas Science and Engineering, vol. 35, pp. 1079-1087, 2016.

[6] W. Meng and C. He, "Back analysis of the initial geo-stress field of rock masses in high geo-temperature and high geostress," Energies, vol. 13, no. 2, p. 363, 2020.

[7] I. L. Pan, "Physical simulation and theoretical estimate of gravity-induced horizontal stress in rocks," Journal of Mining Science, vol. 52, no. 5, pp. 892-898, 2016.

[8] R. Dai, Z. Li, and J. Wang, "Research on initial geo-stress balance method based on abaqus," Journal of Chongqing Technology and Business University: Natural Science Edition, vol. 29, no. 9, pp. 76-81, 2012.

[9] L. Xu, "A general method for the accurate equilibrium of complex initial in-situ stress field," Journal of China Three Gorges University (Natural Sciences), vol. 1, no. 3, pp. 30-33, 2012 .
[10] Y. Guo, W. Zhu, X. Li et al., "Improved regression method for initial geo-stress based on flac3d," Chinese Journal of Geotechnical Engineering, vol. 34, no. 5, pp. 892-898, 2014.

[11] S. D. Akbarov, N. Yahnioglu, and U. B. Yesil, "A 3D fem analysis of stress concentrations around two neighboring cylindrical holes in a prestressed rectangular composite plate under bending," Mechanics of Composite Materials, vol. 48, no. 5, pp. 499-510, 2012.

[12] M. Hou and X. Ge, "Study on fitting analysis of initial stress field in rock masses," Rock and Soil Mechanics, vol. 08, pp. 1626-1630, 2007.

[13] C. Fu, W. Wang, and S. Chen, "Back analysis study on initial geostress field of dam site for xiluodu hydropower project," Chinese Journal of Rock Mechanics and Engineering, vol. 6, no. 11, pp. 2305-2312, 2006.

[14] B. Hu, X. Feng, X. Huang, G. Su, and H. Zhou, "Regression analysis of initial geostress field for left bank high slope region at longtan hydropower station," Chinese Journal of Rock Mechanics and Engineering, vol. 20, no. 22, pp. 4055-4064, 2005.

[15] J. Zhang, Q. Zhang, W. Yang, and X. Zhang, "Regression analysis of initial geostress field in dam zone of dagangshan hydropower station," Rock and Soil Mechanics, vol. 30, no. 10, pp. 3071-3078, 2009.

[16] C. J. Xu, H. B. Ding, W. J. Luo, Li H. Tong, Q. S. Chen, and J. L. Deng, "Experimental and numerical study on performance of long-short combined retaining piles," Geomechanics and Engineering, vol. 20, no. 3, pp. 255-265, 2020.

[17] L. Wang, G. Zheng, and R.-N. Ou, "Differential uplift and settlement between inner column and diaphragm wall in topdown excavation," Journal of Central South University, vol. 22, no. 9, pp. 3578-3590, 2015.

[18] Y. E. Ibrahim and M. Nabil, "Assessment of structural response of an existing structure under blast load using finite element analysis," Alexandria Engineering Journal, vol. 58, no. 4, pp. 1327-1338, 2019.

[19] N. Yan, F. Wei, Y. Ma, and B. Zhu, "Numerical simulation of the construction process of a slurry balance shield traversing under an existing tunnel," Modern Tunnelling Technology, vol. 1, no. 5, pp. 63-69, 2011.

[20] F. Zhu and Y. Wang, "Analysis of the effects of foundation pit construction on the structural deformation of an existing underlying shield tunnel," Modern Tunnelling Technology, vol. 50, no. 3, pp. 94-114, 2013.

[21] W. Ding, L. Zhu, Y. Peng, J. Hu, and C. Yue, "3D numerical analysis of immersed tunnels based on stratum-structure method," Chinese Journal of Geotechnical Engineering, vol. 2013, no. S2, pp. 622-626, 2013.

[22] X. Cui, X. Han, S. Y. Duan, and G. R. Liu, "An abaqus implementation of the cell-based smoothed finite element method (cs-fem)," International Journal of Computational Methods, vol. 17, no. 2, 2020.

[23] Q. Liu, J. Li, and J. Liu, "Paraview visualization of abaqus output on the mechanical deformation of complex microstructures," Computers \& Geosciences, vol. 99, pp. 135-144, 2017.

[24] X. Zhu and J. Wang, "Introduction to partly soil models in abaqus software and their application to the geotechnical engineering," Rock and Soil Mechanics, vol. 174, no. S2, pp. 144-148, 2004. 